\title{
Potentiometric Study of Complexation Between Three Oxime Derivatives and Some Metal Ions in Water-Dioxane Mixed Solvent
}

\author{
ARDESHIR SHOKROLLAHI ${ }^{*}$ and AZADEH NAGHASHIAN HAGHIGHI
}

Department of Chemistry, Yasouj University, 75918-74831, Yasouj, Iran

ashokrollahi@mail.yu.ac.ir

Received 20 May 2012 / Accepted 20 June 212

\begin{abstract}
The complexation equilibria of oximes including 1-phenyl-2-(quinodin-2-yl) ethanoneoxime (pqeo), 2-acetophenone oxime (apo) and 3-nitro benzaldoxime (nbo) with some transition and heavy metal ions such as $\mathrm{Cu}^{2+}, \mathrm{Co}^{2+}, \mathrm{Ni}^{2+}, \mathrm{Zn}^{2+}, \mathrm{UO}_{2}{ }^{2+}$ and $\mathrm{La}^{3+}$ were studied by potentiometric method in water-dioxane mixed solution. All of the titration steps were carried out at $25.0 \pm 0.1{ }^{\circ} \mathrm{C}$ and ionic strength $(\mu)$ of $0.1 \mathrm{M}$ supported by $\mathrm{KNO}_{3}$. The overall stability constants $\log \beta$ of respective species were evaluated by computer refinement of the corresponding potentiometric $\mathrm{pH}$ titration data using BEST computer program. The corresponding distribution diagrams were depicted as a function of $\mathrm{pH}$ by using HySS2009 program. The most likely species were obtained from distribution diagrams and the effect of the oximes structures on the stability constant values were investigated.
\end{abstract}

Keywords: Potentiometric study, 1-Phenyl-2-(quinodin-2-yl) ethanoneoxime, 2-Acetophenone oxime, 3-Nitro benzaldoxime, HySS2009 program

\section{Introduction}

Oximes are a class of chemical compounds with the general formula of $\mathrm{R}_{1} \mathrm{R}_{2} \mathrm{C}=\mathrm{NOH}$, where $\mathrm{R}_{1}$ is an organic side chain and $\mathrm{R}_{2}$ is either hydrogen, forming an aldoxime, or another organic group, forming a ketoxime. Oximes are usually generated by the reaction of hydroxylamine and aldehydes or ketones. Oximes reveal certain insecticidal, matricidal and nematocidal activity such as inhibition of arginase. Some of them are intermediates in the biosynthesis of nitrogen oxide and radiopharmaceuticals in brain tumor diagnostics due to their ability to traverse the blood brain barrier ${ }^{1}$. Oximes are also effectively used as antidotes for nerve agents such as pralidoxime (also known as 2-PAM) (2-((hydroxyimino)methyl)-1methylpyridinium), obidoxime, methoxime, HI-6 (1-((4-(aminocarbonyl)-pyridino) methoxy)methyl)-2(hydroxyimino)methyl)-pyridinium dichloride), Hlo-7 (Pyridinium, 1-(((4-(aminocarbonyl)pyridinio)methoxy)methyl)-2,4-bis((hydroxyimino) methyl)-, diodide) and TMB-4 (trimedoxime bromide). These compounds were also used as antidote against organophosphorus poisons ${ }^{2}$. The metal chelates of oximes exhibited higher antimicrobial activity than free ligands. Biological functions of oximes and their in vivo metabolism are evidently dependent on their chelation with metal ions. Chelating ability of oximes is utilized 
in chemical trace metal analysis, isolation, separation and extraction of various metal ions ${ }^{3}$, therefore, it is useful to obtain the protonation constants $(\mathrm{pKa})$ and stability constants $(\beta)$ of the oximes complex formation with metal ions.

Much attention has been paid to the study of the binary complexes of transition metals with the molecules of biological and pharmaceutical interest ${ }^{4}$ such as oximes. Furthermore, it has been argued that the presence of metal ions in biological fluids could have a significant effect on the therapeutic action of drugs ${ }^{5}$. The stability constants can be of much significance in predicting different chemical processes such as isolation, extraction, or preconcentration methods ${ }^{6}$. Thus, the accurate determination of acidity and stability constants values are fundamental to understanding the behavior of ligands and their interaction with metal ions in aqueous or nonaqueous solutions. The protonation constants of different compounds such as poisons, antidotes, pesticides, drugs, amino acids and nucleic acids predicts the degree of ionization which a molecule will have at a particular $\mathrm{pH}$.

Evaluation of aqueous dissociation constants is an unavoidable requirement in compounds based on oximes development. However, many oximes are sparingly soluble in water and any experimental protonation and stability constants determination requires the use of an organic or hydro organic solvent. Mixtures of water and organic solvent, mainly methanol, ethanol and dioxane are usually employed. The protonation and stability constants values are solvent percent dependent; therefore, these data are very important in biology, agriculture, pharmaceutical industries and spectroscopy ${ }^{7}$. The chromatographic retention and electrophoretic behavior of ionizable compounds, strongly depend on the pKa of the compound and the mobile-phase $\mathrm{pH}^{8}$. Satisfactory knowledge of the acid-base behavior of the substances in hydro-organic media is therefore essential to optimize analytical procedures for the separation of ionizable compounds by $\mathrm{LC}^{9}$ and $\mathrm{CE}^{10}$. Moreover, the acidbase property of a drug molecule is the key parameter for drug development because it governs solubility, absorption, distribution, metabolism and elimination.

Although, the oximes are widely used in various analytical processes such as chromatography $^{11}$, preconcentration, cloud point, solid phase ${ }^{12}$, liquid/liquid extraction, spectrophotometric $^{13}$, voltametric ${ }^{14}$, gravimetric and floating methods ${ }^{15}$ to determine metal ions and are also used to construct different types of sensors such as optodes, ion selective electrodes ${ }^{16}$ and gass sensors, little attention has been paid to the complexation and distribution equilibria related to these systems. Potentiometric titration is accepted as a powerful and simple electroanalytical technique to determine protonation and stability constants. The purpose of this work was to calculate the protonation constants of 1-phenyl2-(quinodin-2-yl) ethanoneoxime (pqeo), 2-acetophenone oxime (apo) and 3-nitro benzaldoxime (nbo) (Figure 1) and stability constants of complex formation of these compounds with some transition and heavy metal ions in water-dioxane mixed solvent by a potentiometric method using BEST program ${ }^{17}$. Corresponding distribution diagrams were drawn by means of HySS2009 as a new version of the older one ${ }^{18}$.

\section{Experimental}

All potentiometric pH measurements were carried out using a Model 794 Metrohm Basic Titrino which was attached to an extension combined glass-calomel electrode mounted in an air-protected, sealed, thermostated jacketed cell maintained at $25.0 \pm 0.1{ }^{\circ} \mathrm{C}$ by circulating water, from a constant-temperature bath Fisherbrand model FBH604, LAUDA, Germany, equipped with a stirrer and a $10.000 \mathrm{~mL}$ capacity Metrohm piston burette. 
<smiles>O/N=C(/Cc1ccc2ccccc2n1)c1ccccc1</smiles>

(a)

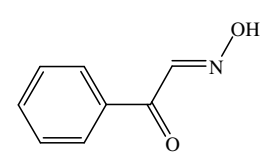

(b)<smiles>O=[N+]([O-])c1cccc(/C=N/O)c1</smiles>

(c)

Figure 1. Chemical structure of: (a) 1-phenyl-2-(quinodin-2-yl) ethanoneoxime (pqeo), (b) 2-acetophenone oxime (apo) and (c) 3-nitro benzaldoxime (nbo)

All common laboratory chemicals used were of reagent grade from Merck Company (Darmstadt, Germany). Analytical grade nitrate or chloride salts of metal ions, potassium hydrogen phetalate (KHP), phenol phetalein, nitric acid, sodium perchlorate, perchloric acid and dioxane with the highest purity available were purchased from Merck Company and used without any further purification. The ligands 1-phenyl-2-(quinodin-2-yl) ethanoneoxime (pqeo), 2-acetophenone oxime (apo) and 3-nitro benzaldoxime (nbo) were synthesized according to the literature ${ }^{19}$. Carbonate free $\mathrm{NaOH}$ solution was standardized with potassium hydrogen phethalate. The $\mathrm{HClO}_{4}$ solution was standardized with standard $\mathrm{NaOH}$. All solutions were prepared in 50\% v/v doubly distilled water-dioxane.

\section{Potentiometric measurements}

The procedure employed for the potentiometric $\mathrm{pH}$ measurements have been described in details elsewhere ${ }^{20}$. In general, an experimental run involves collecting equilibrium data points throughout the entire $\mathrm{pH}$ range, between 2.0 and 14.0 as a function of milliliter standard $\mathrm{NaOH}$ which was added by using the piston burette through a fine capillary tip immersed in the solution. In titration, after each addition, the required time was allowed to reach chemical equilibrium. All potentiometric $\mathrm{pH}$ measurements were made on solutions in a $75-\mathrm{mL}$ doublewalled glass vessel using a Model 794 Metrohm Basic Titrino attached to an extension combined glass-calomel electrode mounted in an air-protected, sealed, thermostated jacketed cell maintained at $25.0 \pm 0.1{ }^{\circ} \mathrm{C}$ by circulating water through the double-walled glass vessel, from a constant-temperature bath Fisherbrand model FBH604, LAUDA, Germany, equipped with a magnetic stirrer and a 10.000-mL-capacity Metrohm piston burette. Atmospheric $\mathrm{CO}_{2}$ was excluded from the titration cell with a purging steam of purified nitrogen gas. The system was maintained at an ionic strength of $0.10 \mathrm{M}$ by $\mathrm{NaClO}_{4}$ as a supporting electrolyte. The $p \mathrm{H}$ meter-electrode system was calibrated to read $-\log \left[\mathrm{H}^{+}\right]^{17}$.

The $\mathrm{pH}$ measurement method for investigating the dependency of complexation to $\mathrm{pH}$ for calculating the protonation constants of pqeo, apo and nbo and stability constants of respective complexes with metal ions was carried out according to the literature ${ }^{21}$. In a typical experiment, a solution containing $2.67 \times 10^{-3} \mathrm{M}$ ligands was placed in the cell, the required amount of $\mathrm{NaClO}_{4}$ (from a $0.50 \mathrm{M}$ stock solution) and $\mathrm{HClO}_{4}(0.10 \mathrm{M}$ ) were added. Finally, the required amount of 50\% v/v doubly distilled deionized water-dioxane was added to the cell to a total volume of $30 \mathrm{~mL}$. The second solution contains the same amounts of component in presence of $1.33 \times 10^{-3} \mathrm{M}$ of each metal ions including $\mathrm{Cu}^{2+}, \mathrm{Co}^{2+}, \mathrm{Ni}^{2+}, \mathrm{Zn}^{2+}$, $\mathrm{UO}_{2}{ }^{2+}$ and $\mathrm{La}^{3+}$ and $50 \% \mathrm{v} / \mathrm{v}$ doubly distilled water-dioxane was added to the same total volume. The potentiometric study was carried out at the metal: ligand molar ratios of 1:2. 
Both solutions were titrated potentiometrically with a $\mathrm{CO}_{2}$ free $0.1 \mathrm{M} \mathrm{NaOH}$ in $50 \%$ $\mathrm{v} / \mathrm{v}$ doubly distilled deionized water-dioxane solution. In all of the systems which were studied, the titrations were performed up to $\mathrm{pH}$ values at which the precipitates formation began and unstable emf measurements were obtained. From the titration curve of the first solution the acidic protonation constants of the ligands and from the second titration curve, the formation constants of different form of complexes were evaluated using BEST program ${ }^{20}$ and corresponding distribution diagrams were drawn by means of Hyss 2009 program as a new version of the old one ${ }^{18}$. BEST program has been used for the potentiometric and solution studies, and calculation of acidic and stability constant of other ligands with some transition and heavy metal ions as reported in our previous publications ${ }^{22}$. The protonation and formation constants of all species were obtained through the least-squares refinement of its $\mathrm{p}\left[\mathrm{H}^{+}\right]$profiles. Throughout this investigation the function minimized was the weighted average of the sums of squares of deviations between calculated and observed $\mathrm{p}\left[\mathrm{H}^{+}\right]$value $\left(\sigma_{\mathrm{fit}}\right)$.

\section{Results and Discussion}

In this study the protonation of three oxime derivatives and their complexation equilibria with some metal ions were investigated by a potentiometric method. Since oximes are mostly insoluble or low dissolved in water the $50 \%$ v/v water-dioxane solvent was used.

\section{Protonation constants}

The protonation equilibrium is as seen in the following equations (Eqs. (1) and (2)) (ligand and proton charges have been omitted for simplicity).

$$
\begin{aligned}
\mathrm{H}+\mathrm{L} & \leftrightarrow \mathrm{HL} \\
\mathrm{H}+\mathrm{HL} & \leftrightarrow \mathrm{H}_{2} \mathrm{~L} \\
\mathrm{H}_{\mathrm{n}-1} \mathrm{~L}+\mathrm{L} & \leftrightarrow \mathrm{H}_{\mathrm{n}} \mathrm{L}
\end{aligned}
$$

And the deprotonation constants $\left(\mathrm{K}_{n} ; \mathrm{n}=1,2\right.$ and 3 for pqeo, $\mathrm{n}=1$ and 2 for apo and nbo) are given as:

$$
\mathrm{K}_{\mathrm{n}}=\frac{\left[\mathrm{H}_{\mathrm{n}-1} \mathrm{~L}\right]\left[\mathrm{H}^{+}\right]}{\left[\mathrm{H}_{\mathrm{n}} \mathrm{L}\right]}
$$

The protonation constants of pqeo, apo and nbo oximes at ionic strength of $0.1 \mathrm{M}$ $\mathrm{NaClO}_{4}$ and temperature of $25{ }^{\circ} \mathrm{C}$ were calculated. The titration data for cited oximes were obtained and the $\mathrm{pH}$ versus volume plots are shown in Figure 2(a-c). The overall and stepwise protonation constants of studied ligands were calculated from computer refinement of $\mathrm{pH}$-volume data using BEST program and the results are presented in Tables 1, 2 and 3. As can be seen, for pqeo three protonation constant values, for apo and nbo two protonation constant values were calculated. Due to similarity of chemical structures of apo and nbo (except for nitro and carboxyl groups), the respective protonation constants values of these two oximes are relatively similar to each other.

In pqeo structure, first protonation constant (12.22) is attributed to the oxygen proton of the oxime group, while the second with the value of 3.61 belongs to the protonation constant of the hydrogen which is attached to the nitrogen of pyridine ring. The third protonation constant (2.64) is attributed to the nitrogen proton of the oxime group. The maximum number of protons attached to apo and nbo is two which are respectively adjoined to the oxygen and nitrogen atoms of the oxime group. 

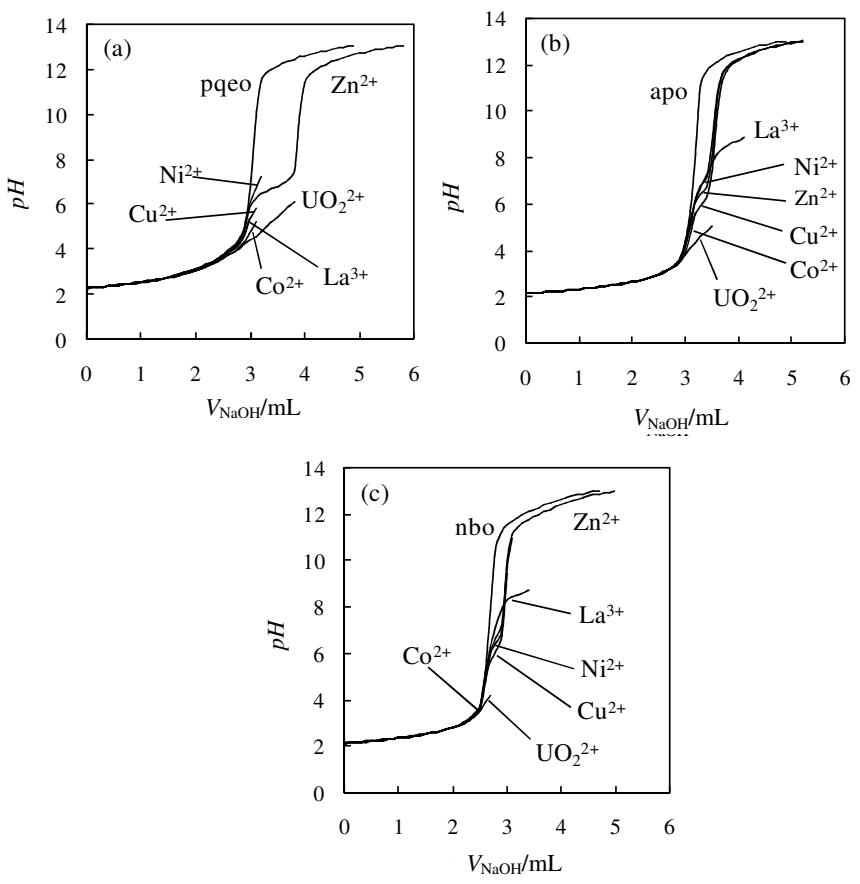

Figure 2. Equilibrium pH titration curves of ligands: (a) pqeo, (b) apo and (c) nbo in the absence and presence of metal ions

Table 1. Overall and stepwise protonation constants for pqeo and overall stability constants for pqeo- $\mathrm{M}^{\mathrm{n}+}$ binary system in $50 \% \mathrm{v} / \mathrm{v}$ water-dioxane mixed solvent at $25{ }^{\circ} \mathrm{C}$ and $\mu=0.1 \mathrm{M}$ $\mathrm{NaClO}_{4}$

\begin{tabular}{cccccccc}
\hline System & $\mathrm{m}$ & $\mathrm{l}$ & $\mathrm{h}$ & $\log \beta$ & $\log K$ & $\operatorname{Max} \%$ & at $\mathrm{pH}$ \\
\hline \multirow{3}{*}{ pqeo } & 0 & 1 & 1 & 12.22 & 12.22 & 100.0 & $7.4-8.3$ \\
& 0 & 1 & 2 & 15.83 & 3.61 & 60.3 & 3.2 \\
& 0 & 1 & 3 & 18.47 & 2.64 & 80.9 & 2.0 \\
& 0 & 1 & 1 & 12.22 & 12.22 & 100.0 & $7.4-8.3$ \\
& 1 & 1 & 0 & 9.24 & - & 26.2 & 6.3 \\
$\mathrm{Co}^{2+}-$ & 1 & 2 & 0 & 17.99 & - & 33.7 & 6.7 \\
pqeo $^{2}$ & 2 & 1 & 1 & 22.22 & - & Neg. & $\ldots$ \\
& 1 & 1 & 0 & 12.88 & - & 20.1 & 5.8 \\
& 1 & 1 & -1 & 18.20 & - & 29.3 & 4.2 \\
& 1 & 1 & -2 & -4.00 & - & 4.7 & 6.8 \\
$\mathrm{Cu}^{2+}-$ & 1 & 2 & 0 & 5.28 & - & 100.0 & $>10.4$ \\
$\mathrm{pqeo}^{2+}$ & 2 & 1 & 0 & 8.90 & - & Neg. & $\ldots$ \\
& 1 & 1 & 1 & 17.74 & - & 25.0 & $\ldots$ \\
& 1 & 1 & -1 & 2.24 & - & 100.0 & $>9.1$ \\
& 1 & -2 & -3.76 & - & 20.9 & 6.4 \\
\hline
\end{tabular}




\begin{tabular}{|c|c|c|c|c|c|c|c|}
\hline \multirow{6}{*}{$\mathrm{La}^{3+}-$ pqeo } & 1 & 1 & 0 & 5.02 & - & Neg. & $\ldots$ \\
\hline & 1 & 2 & 2 & 25.28 & - & Neg. & $\ldots$ \\
\hline & 2 & 1 & 0 & 9.05 & - & Neg. & $\ldots$ \\
\hline & 2 & 1 & 1 & 18.26 & - & 33.7 & 5.4 \\
\hline & 1 & 1 & -1 & 0.46 & - & Neg. & $\ldots$ \\
\hline & 1 & 1 & -2 & -3.98 & - & 100.0 & $>8.0$ \\
\hline \multirow{6}{*}{$\mathrm{Ni}^{2+}-$ pqeo } & 1 & 1 & 0 & 4.07 & - & Neg. & $\ldots$ \\
\hline & 1 & 2 & 2 & 24.04 & - & Neg. & $\ldots$ \\
\hline & 2 & 1 & 0 & 7.22 & - & Neg. & $\ldots$ \\
\hline & 2 & 1 & 1 & 17.36 & - & 18.0 & 5.8 \\
\hline & 1 & 1 & -1 & 0.29 & - & 96.0 & 8.4 \\
\hline & 1 & 1 & -2 & -9.60 & - & 100.0 & $>13.4$ \\
\hline \multirow{6}{*}{$\begin{array}{c}\mathrm{UO}_{2}^{2+}- \\
\text { pqeo }\end{array}$} & 1 & 1 & 0 & 10.38 & - & Neg. & $\ldots$ \\
\hline & 1 & 2 & 1 & 21.47 & - & Neg. & $\ldots$ \\
\hline & 1 & 1 & 0 & 10.38 & - & 53.2 & 5.4 \\
\hline & 2 & 1 & 1 & 18.27 & - & 28.5 & 3.9 \\
\hline & 1 & 1 & -1 & 4.77 & - & 63.3 & 6.3 \\
\hline & 1 & 1 & -2 & -1.97 & - & 100.0 & $>10.3$ \\
\hline \multirow{6}{*}{$\begin{array}{c}\mathrm{Zn}^{2+}- \\
\text { pqeo }\end{array}$} & 1 & 1 & 0 & 4.92 & - & Neg. & $\ldots$ \\
\hline & 1 & 1 & 1 & 10.43 & - & Neg. & $\ldots$ \\
\hline & 2 & 1 & 0 & 8.28 & - & Neg. & $\ldots$ \\
\hline & 2 & 1 & 1 & 17.85 & - & 27.1 & 5.2 \\
\hline & 1 & 1 & -1 & 1.71 & - & 100.0 & 8.7 \\
\hline & 1 & 1 & -2 & -10.64 & - & 97.8 & 14.0 \\
\hline
\end{tabular}

The presence of nitro electron-attractive group in nbo reduces the basicity of this oxime rather than the two other ones. The existence of the carboxyl group in the vicinity of the oxime group in apo structure can distribute and stabilize the negative charge which may be formed on the oxime oxygen via resonance, more easily than pqeo. So the protonation of apo is more difficult than pqeo. Therefore, the protonation constants of cited oximes decrease in the order of pqeo $>a p o \geq$ nbo.

The species distribution diagrams of pqeo, apo and nbo have been shown in Figure 3(a-c). It is obvious that three groups on pqeo are protonated at $\mathrm{pH} 2$ and lead to formation of $\mathrm{LH}_{3}$. The abundance of the species $\mathrm{LH}_{2}$ and $\mathrm{LH}$ reaches to the maximum amount at $\mathrm{pH} 3.2$ and $\mathrm{pH}$ between 7.4-8.3 respectively. Two groups on each ligands, apo and nbo, are protonated at $\mathrm{pH} 2$ and cause the formation of $\mathrm{LH}_{2}$. At higher $\mathrm{pH}$, gradually the protons are loosed and the other various forms including $\mathrm{LH}$ and $\mathrm{L}$ are obtained. The formation of free ligand (L) starts at $\mathrm{pH} 9.8,9.1$ and 9.2 for pqeo, apo and nbo respectively and reaches the maximum concentration at $\mathrm{pH}$ more than 14.0. All of these values which are defined as macrodissociation constants probably belong to the nitrogen atoms (pyridinum and oxime nitrogen), the oxime oxygen in pqeo and the oxime nitrogen and oxygen in apo and nbo. Three equilibrium equations can be written for deprotonation of protonated nitrogen atoms in pqeo ( $\mathrm{LH}$ and $\mathrm{n}=3$ ) and two equilibrium equations can be written for the deprotonation of nitrogen atoms and hydroxyl groups in the two other ligands $\left(\mathrm{LH}_{\mathrm{n}}\right.$ and $\left.\mathrm{n}=2\right)$. 

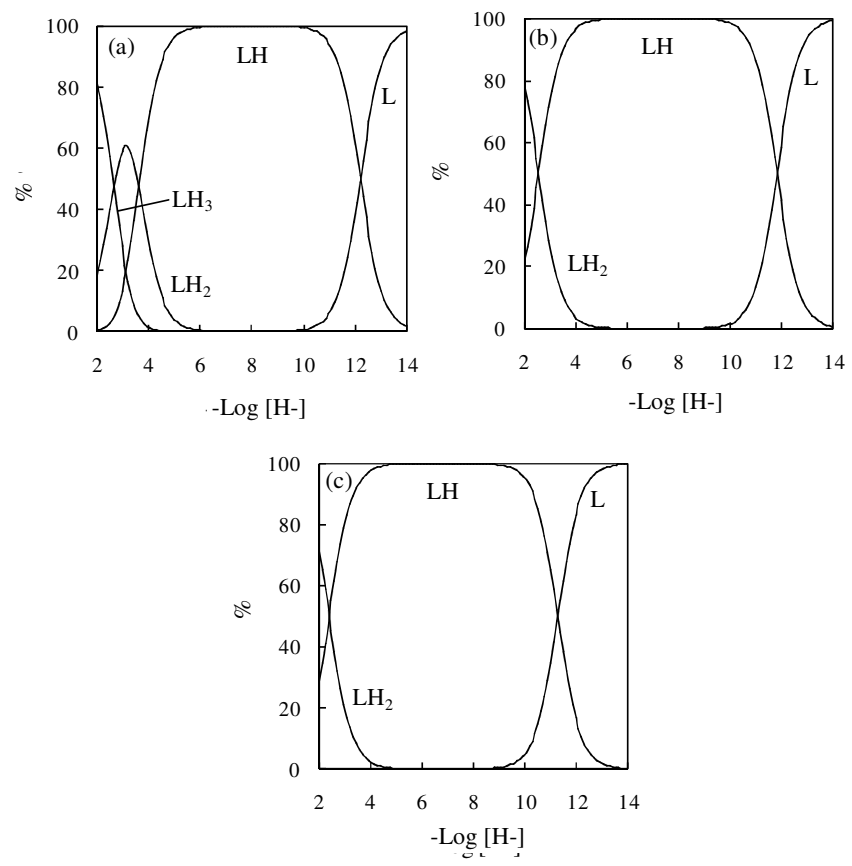

Figure 3. Species distribution diagrams of: (a) pqeo, (b) apo and (c) nbo in 50\% v/v waterdioxane solvent at $25.0 \pm 0.1{ }^{\circ} \mathrm{C}$ and ionic strength of $0.1 \mathrm{M} \mathrm{NaClO}_{4}$

\section{Stability constants of binary complexes}

The formation constants of metal ions and their stoichiometry with pqeo, apo and nbo as binary complexes were determined according to experimental section following refinement of $\mathrm{pH}$-volume data by BEST program. The cumulative stability constants $\left(\beta_{\mathrm{mlh}}\right)$ are defined by Eq. (3) (charges are omitted for simplicity). $m \mathrm{M}+l \mathrm{~L}+h \mathrm{H} \leftrightarrow \mathrm{M}_{m} \mathrm{~L}_{l} \mathrm{H}_{h}$

$$
\beta_{\mathrm{mlh}}=\frac{\left[\mathrm{M}_{\mathrm{m}} \mathrm{L}_{1} \mathrm{H}_{\mathrm{h}}\right]}{[\mathrm{M}]^{\mathrm{m}}[\mathrm{L}]^{1}[\mathrm{H}]^{\mathrm{h}}}
$$

Where $\mathrm{M}$ is metal ion, $\mathrm{L}$ is Ligand and $\mathrm{H}$ is proton and $\mathrm{m}, \mathrm{l}$ and $\mathrm{h}$ are the respective stoichiometric coefficients. Since the ligands and complexes activity coefficients are unknown, the $\beta_{\mathrm{mlh}}$ values are defined in terms of concentrations. In the evaluation of the three component experimental data, the binary complex models were considered as known. The errors are minimized by the use of a high constant ionic strength of $0.1 \mathrm{M}$ $\mathrm{NaClO}_{4}$ and low ligand concentrations. The titration curves are given in Figures $2(\mathrm{a}-\mathrm{c})$. As it is seen in Figure 2, the divergences between the titration curves (in the absence and presence of metal ions) in 50\% v/v water-dioxane solution indicate the interaction between metal ions and pqeo, apo and nbo. The data of such titrations has been used to calculate the equilibrium constants of the respective reactions between the metal ions and ligands.

Titration progress was stopped when the precipitate was seen in solution. Due to the differences between the hydrolysis degrees of the metal ions, in similar conditions, their titration stopping points were different from each other. 


\section{$M^{n+}$-pqeo binary systems}

In the computer refinement of the titration data of $\mathrm{M}^{\mathrm{n}+}$-pqeo binary systems the detectable species are $\mathrm{Cu}_{2} \mathrm{LH}, \mathrm{CuLOH}$ and $\mathrm{CuL}(\mathrm{OH})_{2}$ species in $\mathrm{Cu}^{2+}$-pqeo system, $\mathrm{CoL}, \mathrm{CoL}_{2}, \mathrm{Co}_{2} \mathrm{~L}, \mathrm{Co}_{2} \mathrm{LH}, \mathrm{CoL}(\mathrm{OH})$ and $\mathrm{CoL}(\mathrm{OH})_{2}$ for $\mathrm{Co}^{2+}$-pqeo system, $\mathrm{Ni}_{2} \mathrm{LH}, \mathrm{NiL}(\mathrm{OH})$ and $\mathrm{NiL}(\mathrm{OH})_{2}$ species for $\mathrm{Ni}^{2+}$-pqeo system, $\mathrm{Zn}_{2} \mathrm{LH}, \mathrm{ZnL}(\mathrm{OH})$ and $\mathrm{ZnL}(\mathrm{OH})_{2}$ species for $\mathrm{Zn}^{2+}$-pqeo system, $\mathrm{UO}_{2} \mathrm{~L},\left(\mathrm{UO}_{2}\right)_{2} \mathrm{LH}, \mathrm{UO}_{2} \mathrm{~L}(\mathrm{OH})$ and $\mathrm{UO}_{2} \mathrm{~L}(\mathrm{OH})_{2}$ species for $\mathrm{UO}_{2}{ }^{2+}$-pqeo system and $\mathrm{La}_{2} \mathrm{LH}$ and $\mathrm{LaL}(\mathrm{OH})_{2}$ species for $\mathrm{La}^{3+}$-pqeo system. The species distribution diagram are displayed in Figures $4(\mathrm{a}-\mathrm{f})$ and the respective obtained overall stability constants of these species which are presented in Table 2, show a decrease in these binary systems stability constants for the most metal copmlexes of this oxime are in the order of $\mathrm{UO}_{2}{ }^{2+}>\mathrm{Co}^{2+}>\mathrm{Cu}^{2+}>\mathrm{La}^{3+}>\mathrm{Zn}^{2+}>\mathrm{Ni}^{2+}$. It is obvious that $\mathrm{UO}_{2}{ }^{2+}$ ion makes the most stable complexes with pqeo in comparison with other cited metal ions. It should be noted that the stability constants result from a balance between the binding energy and the solvation energies of all charge species involved in complexation reaction.
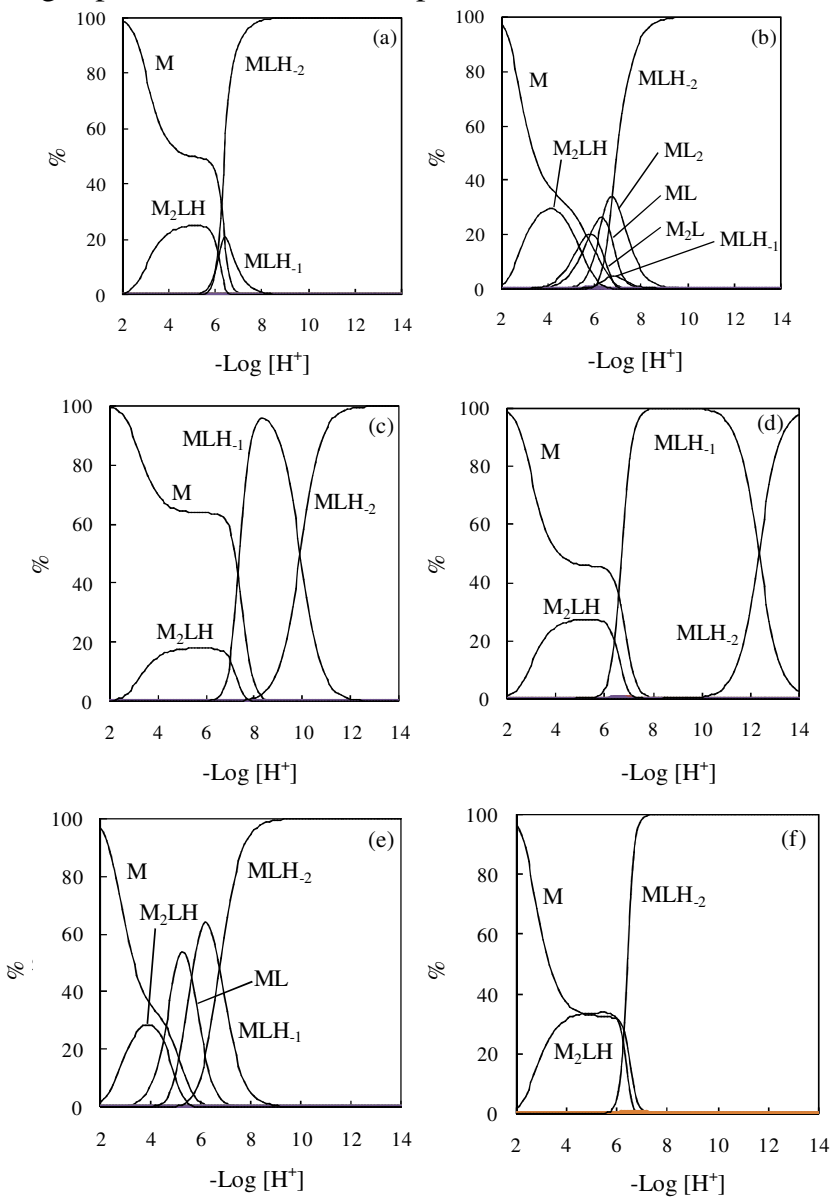

Figure 4. Species distribution diagrams of binary systems of pqeo in presence of: (a) $\mathrm{Cu}^{2+}$, (b) $\mathrm{Co}^{2+}$, (c) $\mathrm{Ni}^{2+}$, (d) $\mathrm{Zn}^{2+}$, (e) $\mathrm{UO}_{2}{ }^{2+}$ and (f) $\mathrm{La}^{3+}$ ions in $50 \% \mathrm{v} / \mathrm{v}$ water-dioxane solvent at 25.0 $\pm 0.1 \circ \mathrm{C}$ and ionic strength of $0.1 \mathrm{M} \mathrm{NaClO}_{4}$ 
Table 2. Overall and stepwise protonation constants for apo and overall stability constants in apo- $\mathrm{M}^{\mathrm{n}+}$ binary system in $50 \%$ v/v water-dioxane mixed solvent at $25^{\circ} \mathrm{C}$ and $\mu=0.1 \mathrm{M} \mathrm{NaClO}_{4}$

\begin{tabular}{|c|c|c|c|c|c|c|c|}
\hline System & $\mathrm{m}$ & 1 & $\mathrm{~h}$ & $\log \beta$ & $\log K$ & Max \% & at $\mathrm{pH}$ \\
\hline \multirow{2}{*}{ apo } & 0 & 1 & 1 & 11.81 & 11.81 & 100.0 & $6.3-8.0$ \\
\hline & 0 & 1 & 2 & 14.37 & 2.56 & 78.5 & 2.0 \\
\hline \multirow{4}{*}{$\mathrm{Co}^{2+}-$ apo } & 1 & 1 & 0 & 9.02 & - & Neg. & $\ldots$ \\
\hline & 1 & 1 & 2 & 20.33 & - & 98.4 & 2.0 \\
\hline & 1 & 2 & 1 & 29.73 & - & 99.9 & $8.5-11.2$ \\
\hline & 1 & 2 & 2 & 31.30 & - & 2.4 & 2.8 \\
\hline \multirow{6}{*}{$\mathrm{Cu}^{2+}-$ apo } & 1 & 1 & 0 & 9.13 & - & 99.3 & $7.9-8.1$ \\
\hline & 1 & 2 & 0 & 13.27 & - & 67.8 & 12.0 \\
\hline & 1 & 2 & 1 & 20.04 & - & Neg. & $\ldots$ \\
\hline & 1 & 2 & 2 & 24.18 & - & Neg. & $\ldots$ \\
\hline & 1 & 1 & -1 & -3.02 & - & 45.9 & 13.5 \\
\hline & 1 & 1 & -2 & -16.79 & - & 57.5 & 14.0 \\
\hline \multirow{7}{*}{$\mathrm{La}^{3+}-$ apo } & 1 & 1 & 0 & 8.45 & - & 57.2 & 7.5 \\
\hline & 1 & 2 & 0 & 15.20 & - & 49.3 & 8.5 \\
\hline & 1 & 2 & 2 & 27.53 & - & 4.1 & 3.8 \\
\hline & 2 & 1 & 0 & 12.04 & - & 26.7 & 6.1 \\
\hline & 1 & 1 & -1 & -2.76 & - & Neg. & $\ldots$ \\
\hline & 1 & 1 & -2 & -9.21 & - & 18.2 & 9.1 \\
\hline & 1 & 2 & -3 & -2.49 & - & 98.8 & $>13.0$ \\
\hline \multirow{5}{*}{$\mathrm{Ni}^{2+}-$ apo } & 1 & 1 & 0 & 8.42 & - & 99.2 & 9.0 \\
\hline & 1 & 2 & 0 & 11.64 & - & 41.7 & 12.3 \\
\hline & 1 & 2 & 1 & 20.53 & - & Neg. & $\ldots$ \\
\hline & 1 & 2 & 2 & 27.19 & - & 2.3 & 4.3 \\
\hline & 1 & 1 & -1 & -4.32 & - & 85.7 & 14.0 \\
\hline \multirow{5}{*}{$\mathrm{UO}^{2+}-$ apo } & 1 & 1 & 0 & 10.35 & - & 71.5 & 4.9 \\
\hline & 1 & 2 & 0 & 16.53 & - & Neg. & $\ldots$ \\
\hline & 1 & 2 & 2 & 27.69 & - & 4.0 & 3.4 \\
\hline & 1 & 1 & -1 & 2.63 & - & Neg. & $\ldots$ \\
\hline & 1 & 1 & -2 & -0.25 & - & 100.0 & $>7.2$ \\
\hline \multirow{6}{*}{$\mathrm{Zn}^{2+}-$ apo } & 1 & 1 & 0 & 8.63 & - & 99.5 & $8.5-9.0$ \\
\hline & 1 & 1 & 1 & 9.31 & - & Neg. & $\ldots$ \\
\hline & 1 & 2 & 0 & 11.96 & - & 43.9 & 12.2 \\
\hline & 1 & 2 & 2 & 27.66 & - & 5.9 & 4.9 \\
\hline & 1 & 1 & -1 & -3.93 & - & 47.7 & 13.4 \\
\hline & 1 & 1 & -2 & -17.55 & - & 68.0 & 14.0 \\
\hline
\end{tabular}

$M^{n+}$-apo binary systems

Potentiometric titration of binary system of respective metal ions including $\mathrm{Cu}^{2+}, \mathrm{Co}^{2+}, \mathrm{Ni}^{2+}$, $\mathrm{Zn}^{2+}, \mathrm{UO}_{2}{ }^{2+}$ and $\mathrm{La}^{3+}$ with apo in $50 \% \mathrm{v} / \mathrm{v}$ water-dioxane solution has been carried out according to experimental section to evaluate the stoichiometry and stability of various species.

The computer refinement of the titration data showed the presence of the species that are listed in Table 3. The concentration distribution diagrams of some binary systems were obtained in the terms of percent metal ions as a $\mathrm{pH}$ function and are shown in Figures 5(a-f). It is observed that by using the calculated values for the stability constants of apo metal complexes in binary systems, the order of stability vary as $\mathrm{UO}_{2}{ }^{2+}>\mathrm{Cu}^{2+}>\mathrm{Co}^{2+}>\mathrm{Zn}^{2+}>$ 
$\mathrm{La}^{3+}>\mathrm{Ni}^{2+}$. As it is obvious $\mathrm{UO}_{2}{ }^{2+}$ ion forms more stable complexes with apo in comparison with other cited metal ions. These orders have relatively good compatibilities with the dispersion of the titration diagrams of apo in the absence and presence of metal ions and also with Irving-Williams series ${ }^{23}$.

Table 3. Overall and stepwise protonation constants for nbo overall stability constants in nbo$\mathrm{M}^{\mathrm{n}+}$ binary system in $50 \% \mathrm{v} / \mathrm{v}$ water-dioxane mixed solvent at $25^{\circ} \mathrm{C}$ and $\mu=0.1 \mathrm{M} \mathrm{NaClO}_{4}$

\begin{tabular}{|c|c|c|c|c|c|c|c|}
\hline System & $\mathrm{m}$ & 1 & $\mathrm{~h}$ & $\log \beta$ & $\log K$ & Max \% & at $\mathrm{pH}$ \\
\hline \multirow[b]{2}{*}{ nbo } & 0 & 1 & 1 & 11.27 & 11.27 & 100.0 & $6.2-7.5$ \\
\hline & 0 & 1 & 2 & 13.66 & 2.39 & 71.2 & 2.0 \\
\hline \multirow{4}{*}{$\mathrm{Co}^{2+}-\mathrm{nbo}$} & 1 & 1 & 0 & 10.80 & - & 9.2 & 14.0 \\
\hline & 1 & 1 & 2 & 20.63 & - & 97.7 & 2.0 \\
\hline & 1 & 2 & 1 & 29.70 & - & 99.5 & $5.5-12.0$ \\
\hline & 1 & 1 & 0 & 7.99 & - & 98.2 & 8.2 \\
\hline \multirow{3}{*}{$\mathrm{Cu}^{2+}-\mathrm{nbo}$} & 1 & 1 & 2 & 14.52 & - & Neg. & $\ldots$ \\
\hline & 1 & 2 & 0 & 11.91 & - & 74.1 & $13.5-14.0$ \\
\hline & 1 & 2 & 1 & 18.35 & - & Neg. & $\ldots$ \\
\hline \multirow{7}{*}{$\mathrm{La}^{3+}-\mathrm{nbo}$} & 1 & 1 & 0 & 6.28 & - & 11.7 & 8.2 \\
\hline & 1 & 2 & 0 & 9.07 & - & Neg. & \\
\hline & 1 & 2 & 1 & 20.89 & - & 29.2 & 8.0 \\
\hline & 2 & 1 & 0 & 10.13 & - & 16.9 & 7.0 \\
\hline & 2 & 2 & 0 & 16.49 & - & 15.3 & 8.2 \\
\hline & 1 & 1 & -1 & -5.17 & - & Neg. & $\ldots$ \\
\hline & 1 & 1 & -2 & -10.24 & - & 100.0 & $>10.2$ \\
\hline \multirow{5}{*}{$\mathrm{Ni}^{2+}-$ nbo } & 1 & 1 & 0 & 7.57 & - & 98.6 & 9.0 \\
\hline & 1 & 2 & 0 & 10.67 & - & 46.8 & $>13.8$ \\
\hline & 1 & 2 & 1 & 18.61 & - & Neg. & $\ldots$ \\
\hline & 1 & 2 & 2 & 22.45 & - & Neg. & \\
\hline & 2 & 2 & 1 & 23.97 & - & 6.5 & 6.3 \\
\hline \multirow{5}{*}{$\mathrm{UO}_{2}{ }^{2+}-\mathrm{nbo}$} & 1 & 1 & 0 & 11.77 & - & 97.9 & 6.4 \\
\hline & 1 & 1 & 2 & 18.61 & - & 80.0 & 2.0 \\
\hline & 1 & 2 & 0 & 17.49 & - & 96.3 & $>13.2$ \\
\hline & 1 & 2 & 2 & 30.39 & - & 52.9 & 3.6 \\
\hline & 2 & 1 & 1 & 20.25 & - & 15.2 & 3.3 \\
\hline \multirow{5}{*}{$\mathrm{Zn}^{2+}-\mathrm{nbo}$} & 1 & 1 & 0 & 7.53 & - & 79.2 & 11.0 \\
\hline & 1 & 2 & 1 & 21.26 & - & 22.8 & $8.2-9.0$ \\
\hline & 1 & 2 & 2 & 26.04 & - & 1.9 & $3.7-4.8$ \\
\hline & 1 & 1 & -1 & -4.78 & - & 28.8 & 12.2 \\
\hline & 1 & 1 & -2 & -16.92 & - & 98.6 & 14.0 \\
\hline
\end{tabular}
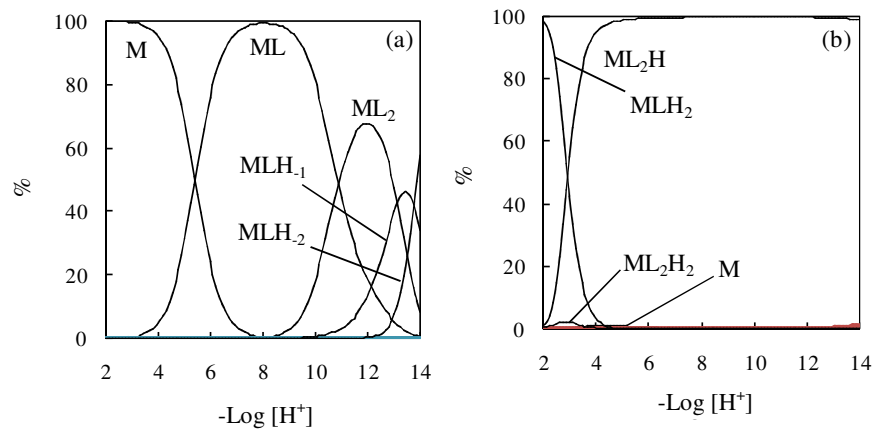

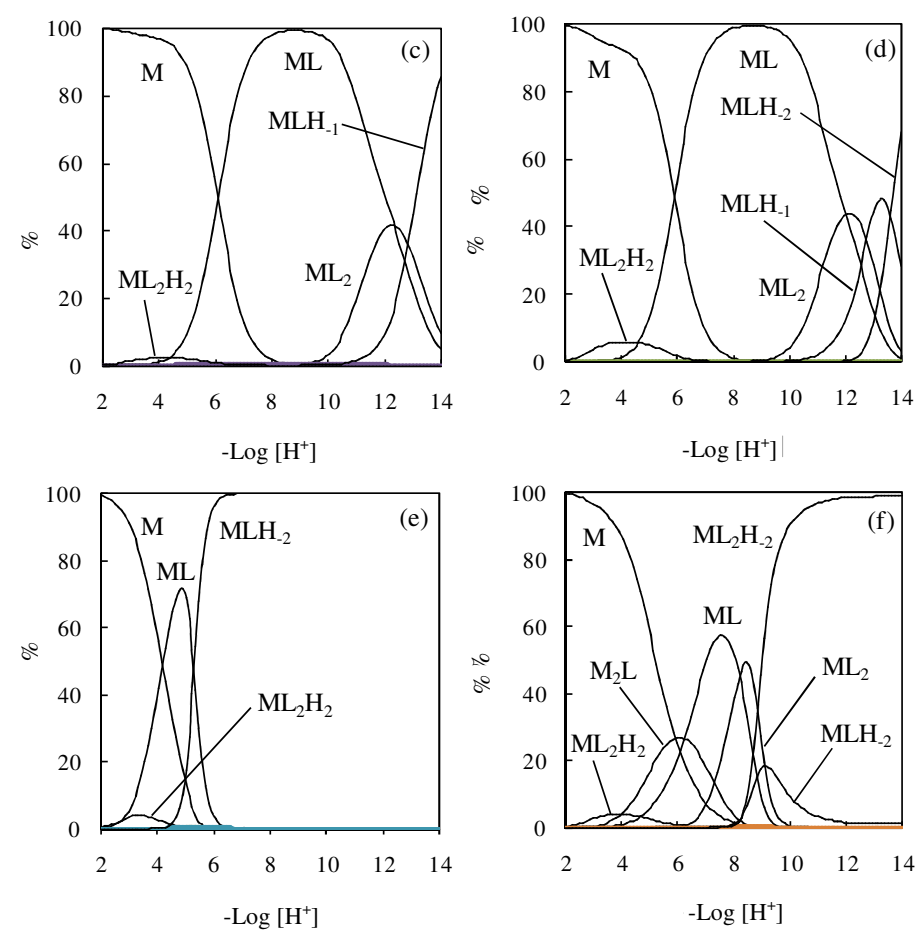

Figure 5. Species distribution curves of binary systems of apo in presence of: (a) $\mathrm{Cu}^{2+}$, (b) $\mathrm{Co}^{2+}$, (c) $\mathrm{Ni}^{2+}$, (d) $\mathrm{Zn}^{2+}$, (e) $\mathrm{UO}_{2}{ }^{2+}$ and (f) $\mathrm{La}^{3+}$ ions in $50 \% \mathrm{v} / \mathrm{v}$ water-dioxane solvent at 25.0 $\pm 0.1{ }^{\circ} \mathrm{C}$ and ionic strength of $0.1 \mathrm{M} \mathrm{NaClO}_{4}$

\section{$M^{n+}$-nbo binary systems}

Overall stability constants for $\mathrm{M}^{\mathrm{n}+}$-nbo binary systems have been calculated in the same way mentioned above. The species which were detected in $\mathrm{M}^{\mathrm{n}+}$-nbo systems and $\log \beta$ values obtained from these calculations for all metal ion-ligand complexes and statistical information of these species are given in Table 4 . The stability constants of the mononuclear complexes for $\mathrm{M}^{\mathrm{n}+}$-nbo system decrease in the order of $\mathrm{UO}_{2}{ }^{2+}>\mathrm{Co}^{2+}>\mathrm{Cu}^{2+}>\mathrm{Ni}^{2+}>\mathrm{Zn}^{2+}>\mathrm{La}^{3+}$ and the corresponding species distribution curves are shown in Figure 6(a-f).
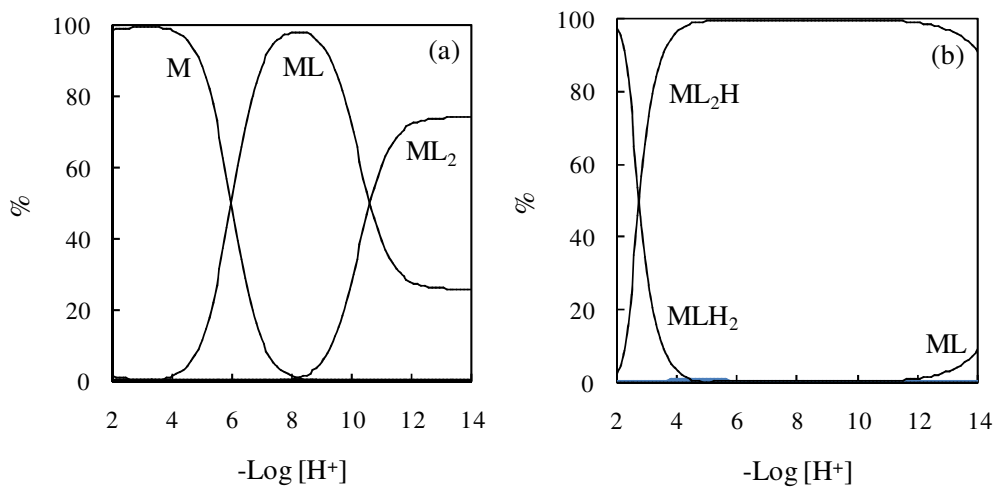

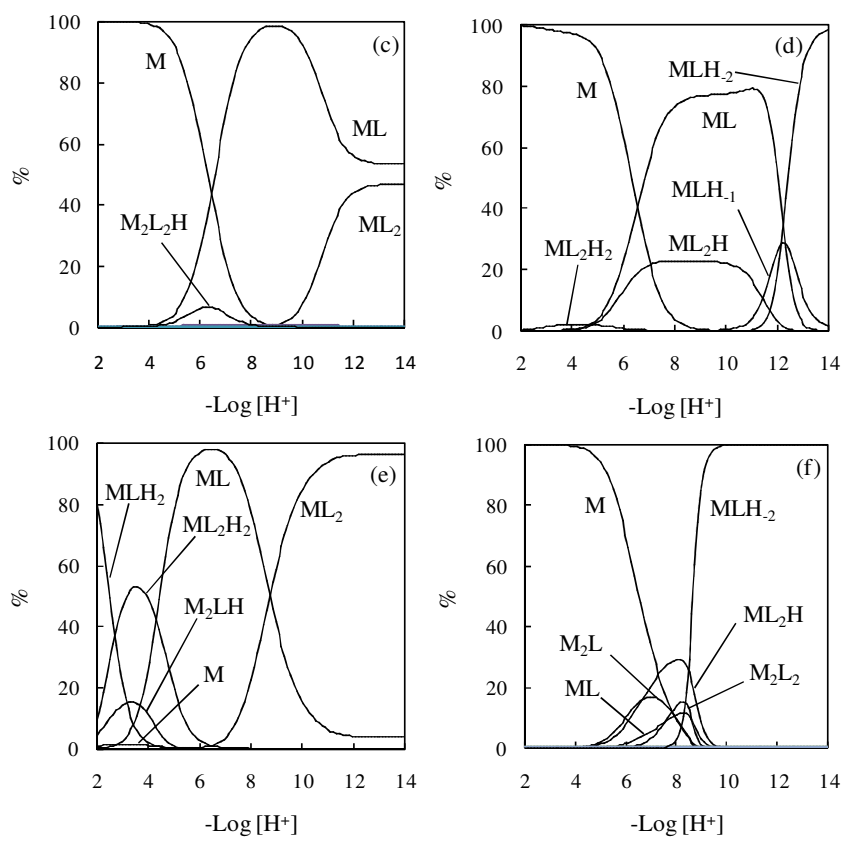

Figure 6. Species distribution curves of binary systems of nbo in presence of: (a) $\mathrm{Cu}^{2+}$, (b) $\mathrm{Co}^{2+}$, (c) $\mathrm{Ni}^{2+}$, (d) $\mathrm{Zn}^{2+}$, (e) $\mathrm{UO}_{2}{ }^{2+}$ and (f) $\mathrm{La}^{3+}$ ions in $50 \% \mathrm{v} / \mathrm{v}$ water-dioxane solvent at 25.0 $\pm 0.1 \circ \mathrm{C}$ and ionic strength of $0.1 \mathrm{M} \mathrm{NaClO}_{4}$

According to the obtained complexes stabilities for each metal ion, the effect of ligands structures on the complexes stability constants can be investigated. Due to the presence of carbonyl oxygen in the vicinity of oxime nitrogen or oxygen in apo structure in comparison with pqeo, it forms five or six-member chelate rings with metal ions. On the other hand, the existence of nitro electron-attractive group in nbo structure reduces the stability of these ligand complexes with metal ions. The presence of pyridine ring in addition to the oxime oxygen in pqeo structure provides good conditions for the formation of $\mathrm{ML}_{2}$ species of pqeo with cited metal ions.

The oxime group has two donor atoms, $\mathrm{N}$ and $\mathrm{O}$, which may coordinate to a metal ion through either or both as unidentate or bidentate respectively. The different coordination modes of oxime and oximato species, depicted in Figure 7 indicate a versatile electronic distribution within the ligands. This, in turn, suggests that the chemistry of metal-bonded oximes should be rich. The inspection of data accumulated in the literature confirms this assumption ${ }^{24}$.<smiles>[M]O/N=C(/C)O[W]</smiles><smiles></smiles>

Figure 7. Coordination modes of oxime and oximato species with metal ion(s) 
The stability constants orders of these three oximes complexes with cited metal ions have relatively good compatibilities with Irving-Williams series ${ }^{23}$. Relative deviation from Irving-Williams series has been seen in in literature about some of other oximes ${ }^{25}$.

\section{Conclusion}

The protonation constants of the ligands and formation constants of the resulting complexes were computed from $\mathrm{pH}$-volume titration data using BEST program. The computer refinement of the titration data showed the presence of $\mathrm{ML}, \mathrm{MLH}_{2}, \mathrm{ML}(\mathrm{OH}), \mathrm{ML}(\mathrm{OH})_{2}$, $\mathrm{ML}_{2}, \mathrm{ML}_{2} \mathrm{H}, \mathrm{ML}_{2} \mathrm{H}_{2}, \mathrm{M}_{2} \mathrm{~L}$ and $\mathrm{M}_{2} \mathrm{LH}$ species in binary systems. The distribution diagram of detectable species in absence and presence of metal ions as a function of $\mathrm{pH}$ was given by using HySS2009 program.

The speciation studies indicate that there is a relatively strong interaction between $\mathrm{UO}_{2}{ }^{2+}$ and pqeo, apo and nbo in $50 \% \mathrm{v} / \mathrm{v}$ water-dioxane solution containing sodium perchlorate as constant ionic medium rather than other metal ions considered in this study. The order of resulting stability constants for the cited $\mathrm{M}^{2+}$-oxime systems, have relatively good compatibilities with Irving-Williams series. Relative deviation from these series has been reported in literature about some of other oximes.

\section{Acknowledgement}

The authors gratefully acknowledge the support of this work by the Yasouj University Research Council for financial support.

\section{References}

1. Blower P J, Trans Met Chem., 1998, 23, 109.

2. Rachaman E S, Ashani Y, Leader H, Granoth I, Edery H and Porath G, Arzneim Forsch., 1979, 29, 875.

3. Filippov L O, Joussemet R and Houot R, Miner Eng., 2000, 13, 37.

4. Ghandour M A, Aboul-kasim E A, Ameralla A H, AbdallaN A and Farghaly O A, Assiut University Second Pharmaceutical Conference, Assiut, Egypt, March, 2000, 8-9, 115.

5. Kirschner S, Wei K Y, Francis D and Bergam G J, J Med Chem., 1966, 9, 369.

6. Gracia E A and Gomis D B, Mikrochem Acta, 1996, 124, 179-185.

7. GuillénSans R and GuzmánChozas M, Microchem J., 1988, 37, 40.

8. Erdemgil F Z, Sanli S, Sanli N, Ozkan G, Barbosa J, Guiteras J and Beltran J L, Talanta, 2007, 72(2), 489-496.

9. Janos P, J Chromatogr A, 2004, 1037, 15.

10. Andrasi M, Buglyo P, Zekany L and Gaspar A, J Pharm Biomed Anal., 2007, 44(5), 1040-1047.

11. Lewis R J, Johnson R D and Hattrup R A, J Chromatogr B, 2005, 822(1-2), 137-145.

12. GhasemiJ B and Zolfonoun E, Talanta, 2010, 80, 1191.

13. Ghaedi M, Shokrollahi A and EkrampourFand Aghaei R, Bull Chem Soc Ethiop., 2009, 23, 337-345.

14. Ghaedi M, Amini M K, Rafi A, Gharaghani S and Shokrollahi A, Ann Chim., 2005, 95(6), 457-464.

15. Karimi H, Ghaedi M, Shokrollahi A, Rajabi H R, Soylak M, Karami B, J Hazard Mater., 2008, 151, 26-32.

16. Yari A and AziziSand Kakanejadifard A, Sens Actuators B, 2006, 119, 167-173.

17. Motekaitis R J and Martell A E, Can J Chem., 1982, 60, 2403. 
18. Alderighi L, Gans P, Ienco A, Peters D, Sabatini A and Vacca A, Coord Chem Rev., 1999, 184, 311.

19. Corsaro A, Chiacchio U and Pistara V, Synthesis, 2001, 13, 1903-1931.

20. Martell A E and Motekaitis R J, Determination and Use of Stability Constants, VCH, New York, USA, 1992.

21. Schwarzenbach G and Flaschka H, Complexometric Titrations, Methuen, London, UK, 1969.

22. Shokrollahi A, Ghaedi M, Niband M S and Rajabi H R, J Hazard Mater., 2008, 151(2-3), 642-648.

23. Irving H and Williams R G P, J Am Chem Soc., 1953, 637, 3192-3210.

24. Kukushkin V Y, Tudela D and Pombeiro A J L, Coord Chem Rev., 1996, 156, 333.

25. Shokrollahi A, Ghaedi M, Rajabi H R andNiband M S, Spectrochim Acta Part A, 2008, 71, 655-662. 